\title{
Fabrication and characterization of Ag-Sr doped hydroxyapatite/chitosan coatings deposited on 316L SS via electrophoretic deposition
}

Muhammad Whaj ${ }^{1, \mathrm{a}}$, Usama Saleem ${ }^{1, \mathrm{a}}$, Farasat Iqbal ${ }^{2 *}$, Muhammad Yasir ${ }^{1}$, Abdul wadood $^{1}$, Muhammad Atiq Ur Rehman ${ }^{1 *}$

${ }^{1}$ Department of Materials Science and Engineering, Institute of Space Technology Islamabad, 1, Islamabad Highway, Islamabad 44000

2 Interdisciplinary Research Centre in Biomedical Materials, COMSATS University Islamabad, Lahore Campus

${ }^{a}$ Both the authors contributed equally

* Corresponding author: atique1.1@ hotmail.com 


\begin{abstract}
In this study, silver-strontium doped hydroxyapatite (AgSr-HA)/chitosan composite coatings were deposited on stainless steel (SS) substrate via electrophoretic deposition (EPD) technique. The EPD parameters such as the concentration of Ag Sr-HA particles in the suspension, applied voltage and deposition time were optimized on by the Taguchi Design of Experiment (DoE) approach. DOE approach elucidated that the "best" coating was obtained at; the deposition voltage of $20 \mathrm{~V}$, deposition time of 7 minutes, and at $5 \mathrm{~g} / \mathrm{L}$ of $\mathrm{Ag} \mathrm{Sr}-\mathrm{HA}$ particles in the suspension. The optimum coatings were characterized by using scanning electron microscopy (SEM) and energy dispersive Xray (EDX) spectroscopy. SEM images confirmed the deposition of chitosan/Ag Sr-HA on the SS substrate. The wettability studies indicated the hydrophilic nature of the chitosan/Ag Sr-HA coatings, which confirmed the suitability of the developed coatings for orthopedic applications. The average surface roughness of the chitosan/Ag Sr-HA coatings was in a suitable range for the attachment of bone marrow stromal cells. Chitosan/Ag Sr-HA coatings showed a potent antibacterial effect against the Gram-Positive and Gram-negative bacteria.
\end{abstract}

Keywords: Electrophoretic deposition; design of experiment; hydroxyapatite; chitosan; antibacterial 


\section{Introduction}

According to a new report published by Allied Market Research, the orthopedic implants market size was valued at $\$ 45,901$ million in 2017 , and is estimated to reach $\$ 66,636$ million by 2025 , growing at annual growth rate of $4.7 \%$ from 2018 to 2025.The major factors that depends upon the growth of the global orthopedic implants market are rise in the spreading of orthopedic injuries and diseases and the rapid rise in older population ${ }^{1}$.

The first metallic materials successfully used during the twentieth century in orthopedic applications were stainless steel and cobalt-chrome-based alloys ${ }^{2}$. The first really successful substitutive joint prosthesis was the total hip prosthesis developed by Charnley in the late $1950 \mathrm{~s}^{3}$. This was a cemented prosthesis with a stem made of stainless steel. Stainless steel materials are resistant to a wide range of corrosive agents due to their high $\mathrm{Cr}$ content (more than $12 \mathrm{wt} \%$ ), which allows the formation of a strongly adherent, self-healing and corrosion resistant coating oxide of $\mathrm{Cr}_{2} \mathrm{O}_{3}{ }^{45}$. Several types of stainless steel are available and the most widely used for implant manufacture is austenitic stainless steel. In order to be austenitic at room temperature, stainless steel needs to contain a certain amount of austenite stabilizing elements such as $\mathrm{Ni}$ or $\mathrm{Mn}^{6}$. The stainless steel most widely used in orthopedic applications is AISI 316L that contains $0.03 w t \% \mathrm{C}, 17-20 \mathrm{wt} \% \mathrm{Cr}, 12-14 \mathrm{wt} \% \mathrm{Ni}, 2-$ $3 \mathrm{wt} \%$ Mo and minor amounts of nitrogen, manganese, phosphorus, silicon and Sulphur ${ }^{7,8}$.

Stainless steel is widely used in traumatological temporary devices such as fracture plates, screws and hip nails among others, owing to their relatively low cost, availability and easy processing. Their use in orthopedic joint prosthesis is restricted because other metallic alloys such as Ti-based and Co-Cr-based alloys exhibit superior mechanical and corrosion properties ${ }^{8,9}$ At present, new austenitic stainless steel with high Cr content (over 20\%), where Ni has been partially substituted by 
Mn and with a high Ni content (between 0.3 and $0.4 \%$ ), is being used in joint prosthesis. Ni stabilizes the austenitic phase and induces an increase in both the corrosion resistance and the mechanical properties (yield stress) ${ }^{10}$. This is a clear example of new materials with an improved performance that have been developed chronologically during the second generation, but that from a conceptual point of view belong to the first generation ${ }^{11}$.

Type 316L stainless steel (316L SS) is a widely used material for implant fabrication in orthopedic applications. It possesses good inherent mechanical properties, reasonable corrosion resistance, biocompatibility and suitable density for load bearing purposes ${ }^{12}$.

Chitosan is a polymer that has been used extensively both in nucleic acid delivery and tissue engineering applications, derived from the exoskeleton of marine animals such as crab, shrimp, lobster, and krill. Chitosan is biodegradable, biocompatible and non-toxic ${ }^{12,13}$.

On the other hand, Hydroxyapatite (HA) has generated great interest as an advanced orthopedic and dental implant candidate. HA can be chosen as biocompatibility symbol as its chemical composition is similar to the mineral part of bone and tooth tissue ${ }^{14}$. HA has also been substituted with various metallic ions to have therapeutic effect. For example, the incorporation of strontium improves the bioactivity of $\mathrm{HA}{ }^{14,15}$. The incorporation of $\mathrm{Zn}, \mathrm{Ag}$ and copper in the $\mathrm{HA}$ is known to provide antibacterial effect against broad spectrum of bacteria ${ }^{16}$.

Electrophoretic deposition (EPD) is one of the colloidal processing techniques and has advantages of short formation time and needs simple apparatus and no or little restrictions on the substrate material and shape. Despite the simplicity of the process, many parameters influence the deposition rate and quality of the deposited layer in EPD. The characteristics and concentration of solid particles in the suspension, the electrophoretic mobility, the suspension conductivity, $\mathrm{pH}$, electric field, and 
deposition time control the EPD rate. Therefore, to obtain a controlled deposition rate leading to desirable coating microstructure, optimization of the processing parameters is necessary ${ }^{17,18}$. In order to control the EPD process Taguchi design of experiment (DoE) approach has been used for achieving homogenous coatings ${ }^{2,7,13}$.

Here, we develop antibacterial coatings on the surgical grade 316L SS substrate via EPD. EPD process was optimized via Taguchi DoE approach to achieve the coatings with the highest deposition yield with the lowest possible standard deviation. Coatings obtained from the optimum EPD parameters and suspension composition were fairly homogeneous with coating thickness of $\sim 5 \mu \mathrm{m}$. The coatings presented suitable wettability and roughness for the biomedical applications. Chitosan/Ag Sr-HA coatings showed antibacterial effect against Gram-positive and Gram-negative bacteria.

\section{Materials and Methods}

\subsection{Suspension preparation}

For the preparation of the chitosan solution, $0.5 \mathrm{~g} / \mathrm{L}$ chitosan (medium molecular weight, 75-85\% deacetylation degree, Sigma-Aldrich) was dissolved in 20 Vol. \% distilled water (ELGADV 25 PURELAB option R7BP) and 1 Vol. \% acetic acid (VWR International) by magnetic Stirring for 30 minutes. Later, 79 Vol \% ethanol (ethanol absolute $\geq 99.8 \%$, VWR International) was added to the chitosan solution, to reduce the undesired hydrolysis of water during the EPD process, It is important to mention that the concertation of chitosan $(0.5 \mathrm{~g} / \mathrm{L})$ in suspension was chosen based on suspension stability and the fact that higher concentration of chitosan led to the production of inhomogeneous coatings $^{19}$.

\subsection{Preparation of Ag $\mathrm{Sr}-\mathrm{HA}$ /chitosan solution:}


Ag Sr-HA /chitosan suspension was prepared by adding Ag Sr-HA (HA doped with 8 mol.\% Sr and $1 \mathrm{~mol} . \% \mathrm{Ag}$ ) in the prepared chitosan solution. The details on the synthesis of the HA powder have recently been published ${ }^{20}$. Ag Sr-HA was added into the prepared chitosan solution in for different concentrations i.e. $1 \mathrm{wt} \%, 3 \mathrm{wt} \%, 5 \mathrm{wt} \%$ and $7 \mathrm{wt} \% \mathrm{Ag}$ Sr-HA. The suspension was magnetically stirred for 5 minutes and then ultra-sonicated for one hour to ensure the uniform dispersion of solid particles, following the previous studies ${ }^{1,19}$.

\subsection{Electrodes preparation}

A 316L SS sheet is cut into dimensions of $3 \times 2.5 \mathrm{~cm}$ using a sheet cutter. The electrodes were then immersed in the mixture of ethanol and acetone for 5-10 minutes. After that, the electrodes were dried with hot air.

\subsection{EPD setup}

316L SS substrates were coated with chitosan/ Ag Sr-HA composite via EPD. The EPD process was carried out in a two-electrode cell, where $316 \mathrm{~L}$ SS was used as a cathode and the $316 \mathrm{~L}$ SS plate was uses as an anode. The inter-electrode distance was kept at $1 \mathrm{~cm}$. The electrodes were connected to a DC power supply (EX735 M Multi-Mode PSU 75 V/150 V $300 \mathrm{~W}$, Thurlby Thandar Instruments Limited), and the current was monitored over time with a multimeter (1906 Bench Digital Multimeter Thurlby Thandar Instruments Limited).

\subsubsection{Taguchi Design of Experiment (DoE) Approach}

A Taguchi array of experiments was formed for the optimization of EPD parameters using Minitab17 TM software. An orthogonal Taguchi array ( $\mathrm{L}^{16}$ type) was constructed from 3 control factors (voltage, time and concentration of $\mathrm{Ag} \mathrm{Sr} \mathrm{HA}$ in the suspension); each had 4 levels, as illustrated in Table 1. 
Table 1. Control factors and their different levels applied for depositing chitosan/Ag Sr-HA coatings on $316 \mathrm{~L} \mathrm{SS}$ substrates.

\begin{tabular}{|l|l|l|l|l|}
\hline Control factors & Level 1 & Level 2 & Level 3 & Level 4 \\
\hline Concentration of Ag & 1 & 3 & 5 & 7 \\
Sr-HA in the & & & & \\
Suspension(g/L) & & & & 40 \\
\hline Voltage(V) & 10 & 20 & 30 & 9 \\
\hline
\end{tabular}

The input factors (applied voltage, deposition time, and concentration of $\mathrm{Ag} \mathrm{Sr}-\mathrm{HA}$ in the suspension) are systematically changed and their influence on the output factor (mass of the composite coating) was examined. If the concentration of $\mathrm{Ag}$ Sr-HA was higher than $7 \mathrm{~g} / \mathrm{L}$, it was impossible to obtain stable suspensions and sedimentation of Sr-Ag HA particles was observed. On the other hand, high voltages applied during EPD caused the generation of gas bubbles at the surface of the substrate. Based on DoE, 16 experimental runs were carried out, as shown in the Table 2.

Table 2. Taguchi DOE array for EPD of chitosan/AgSr-HA on 316L SS substrates.

\begin{tabular}{|c|c|c|c|}
\hline $\begin{array}{l}\text { Exp. } \\
\text { No. }\end{array}$ & $\begin{array}{l}\text { Conc. Of Ag Sr-HA in the } \\
\text { suspension (g/L) }\end{array}$ & $\begin{array}{l}\text { Voltage } \\
\text { (V) }\end{array}$ & $\begin{array}{l}\text { Time } \\
\text { (minutes) }\end{array}$ \\
\hline $\mathbf{1}$ & 1 & 10 & 3 \\
\hline $\mathbf{2}$ & 1 & 20 & 5 \\
\hline $\mathbf{3}$ & 1 & 30 & 7 \\
\hline $\mathbf{4}$ & 1 & 40 & 9 \\
\hline $\mathbf{5}$ & 3 & 10 & 5 \\
\hline
\end{tabular}




\begin{tabular}{|c|c|c|c|}
\hline $\mathbf{6}$ & 3 & 20 & 3 \\
\hline $\mathbf{7}$ & 3 & 30 & 9 \\
\hline $\mathbf{8}$ & 3 & 40 & 7 \\
\hline $\mathbf{9}$ & 5 & 10 & 7 \\
\hline $\mathbf{1 0}$ & 5 & 20 & 9 \\
\hline $\mathbf{1 1}$ & 5 & 30 & 3 \\
\hline $\mathbf{1 2}$ & 5 & 40 & 5 \\
\hline $\mathbf{1 3}$ & 7 & 10 & 9 \\
\hline $\mathbf{1 4}$ & 7 & 20 & 7 \\
\hline $\mathbf{1 5}$ & 7 & 30 & 5 \\
\hline $\mathbf{1 6}$ & 7 & 40 & 3 \\
\hline
\end{tabular}

Each experiment was repeated thrice. Thus, 48 experiments were performed and the substrate were weighed before and after the coating with the help of weighing balance (the accuracy was $0.1 \mathrm{mg}$ ). After repeating each experiment thrice, average value of deposition yield, signal to noise ratio $(\mathrm{S} / \mathrm{N})$ for deposition yield \& standard deviation was calculated by using the Equation 1, Equation 2, and Equation 3, respectively

$$
\text { Deposition yield }=\Delta \text { Weight } / A \text { in }\left(\frac{m g}{c m 2}\right) \text { Equation } 1
$$

Where; $\Delta$ Weight $=$ weight after coating - weight before coating, and $\mathrm{A}=$ Area of coating It was desired to achieve higher values of deposition yield and a low standard deviation. The signal to noise ratio $(\mathrm{S} / \mathrm{N})$ for the deposition yield was calculated using the Equation (2)

$$
\frac{S}{N} \text { ratio of deposition yield }=-10 \log \left[\frac{1}{n}\left(\sum 1 / y^{2}\right)\right] \text { Equation } 2
$$


Where; $\mathrm{y}=$ deposition yield and $\mathrm{n}=$ No. of observations.

The $\mathrm{S} / \mathrm{N}$ ratio for the standard deviation was calculated from the Equation (3):

$$
\frac{s}{N} \text { ratio of deposition yield }=-10 \log \left[\frac{1}{n}\left(\sum y^{2}\right)\right] \text { Equation } 3
$$

Where; $\mathrm{y}=$ standard deviation and $\mathrm{n}=$ no. of observations

\subsection{Characterization of chitosan/ Ag Sr-HA composite coatings}

The morphology and structure of the obtained coatings were examined by field emission scanning electron microscopy (FE-SEM) and compositional analysis was performed by energy-dispersive Xray spectroscopy (EDS) (Hitachi S-4700 with a Noran System 7). The zeta potential of the chitosan/Ag Sr HA was evaluated by the the zeta potentials of the chitosan solution and suspensions were measured (Malvern Instruments, UK). Contact angle measurements were carried out on a contact angle goniometer using a sessile drop technique (DSA30 Kruess GmbH, Germany). Deionized water droplets (volume of one drop $=5 \mu \mathrm{L}$ ) were used to determine the wettability of coatings. The measurements were repeated for three different samples. Surface roughness measurements were carried out by using a laser profilometer (UBM ${ }^{\mathrm{TM}}$, ISC-2). A measurement length of 5-7 mm was used with a scanning velocity of 400 points per second. The mean roughness (Ra) and maximum roughness (Rmax) values were calculated using LMT Surface View UBM ${ }^{\mathrm{TM}}$ software.

The agar disk diffusion test was performed on chitosan (control sample) and on chitosan/ Ag Sr-HA coatings. Prior to this study, coatings were sterilized under UV light for 1 hour. Agar plates were filled with $20 \mathrm{~mL}$ of agar and then $20 \mu \mathrm{L}$ of LB-media (Gram negative bacteria: Escherichia coli; Gram positive: Staphylococcus carnosus) with the optical density of $0.015\left(\mathrm{OD}_{600}\right)$ was spread 
homogeneously on agar plate. Samples were placed on the prepared agar plate, which were kept in the incubator at $37{ }^{\circ} \mathrm{C}$ for 24 hours. After 24 hours of incubation, the zones of inhibition were measured by using 'ImageJ' analysis (each test was performed in triplicate), following the previous studies ${ }^{21,22}$.

\section{Results and Discussion}

\subsection{DoE study of EPD of chitosan/SrAg-HA}

For optimization of the EPD parameters and suspension, the Taguchi DoE approach was used to end up with a high deposition rate and low standard deviation of chitosan/Ag Sr-HA coatings. Taguchi array of L16 was built for these control factors i.e., concentration, voltage and time. These 16 experiments performed under the given Taguchi array and determined the corresponding deposition yield and standard deviation, as reported in Table 3.

Table 3. Experimentally measured values of deposition yield and corresponding standard deviations for EPD of chitosan/SrAg-HA coatings.

\begin{tabular}{|l|l|l|l|l|l|l|l|}
\hline Run & \multicolumn{2}{|l|}{ Control factors } & Deposition & S/N ratio & Standard & S/N ratio \\
\cline { 2 - 7 } & SrAg-HA & Voltage & Time & yield in $/$ & $(\mathrm{dB})$ & deviation & $(\mathrm{dB})$ \\
\hline 1 & 1 & 10 & 3 & 0.027273 & -31.2853 & 0.005143 & 45.7757 \\
\hline 2 & 1 & 20 & 5 & 0.028485 & -30.9077 & 0.008176 & 41.7492 \\
\hline 3 & 1 & 30 & 7 & 0.075758 & -22.4114 & 0.011999 & 38.4171 \\
\hline 4 & 1 & 40 & 9 & 0.074545 & -22.5516 & 0.018953 & 34.4464 \\
\hline 5 & 3 & 10 & 5 & 0.014545 & -36.7457 & 0.005353 & 45.4281 \\
\hline 6 & 3 & 20 & 3 & 0.032727 & -29.7019 & 0.009271 & 40.6575 \\
\hline
\end{tabular}




\begin{tabular}{|l|l|l|l|l|l|l|l|}
\hline 7 & 3 & 30 & 9 & 0.167879 & -15.5001 & 0.009544 & 40.4054 \\
\hline 8 & 3 & 40 & 7 & 0.189697 & -14.4388 & 0.01487 & 36.5538 \\
\hline 9 & 5 & 10 & 7 & 0.046061 & -26.7333 & 0.01245 & 38.0966 \\
\hline 10 & 5 & 20 & 9 & 0.165455 & -15.6264 & 0.031422 & 30.0553 \\
\hline 11 & 5 & 30 & 3 & 0.128485 & -17.8230 & 0.033929 & 29.3886 \\
\hline 12 & 5 & 40 & 5 & 0.273939 & -11.2469 & 0.045426 & 26.8539 \\
\hline 13 & 7 & 10 & 9 & 0.050909 & -25.8641 & 0.008266 & 41.6541 \\
\hline 14 & 7 & 20 & 7 & 0.207273 & -13.6691 & 0.024529 & 32.2064 \\
\hline 15 & 7 & 30 & 5 & 0.296364 & -10.5635 & 0.067068 & 23.4697 \\
\hline 16 & 7 & 40 & 3 & 0.227879 & -12.8459 & 0.048704 & 26.2487 \\
\hline
\end{tabular}

The effect of these control factors on the deposition yield is shown in Figure 1. Figure 1 demonstrates that the mean response of deposition yield was the highest for A4 (Ag Sr-HA concentration of 7g/l), B4 (applied voltage of $40 \mathrm{~V}$ ) and C2 (deposition time of 5 minutes) conditions and S/N response of the deposition yield was maximum for A4, B4, and C3 (7 minutes) conditions. This means there is no major difference between the results of mean and $\mathrm{S} / \mathrm{N}$ values of deposition yield. Moreover, it also shows that the deposition yield increases by increasing concentration and voltage which obeys the Hamaker's law. The maximum-minimum mean and S/N response of deposition yield suggested that the voltage is the most effective parameter (rank 1) followed by the deposition time and SrAgHA concentration (Table 4 and Table 5). This observation also estimates that $\mathrm{S} / \mathrm{N}$ and mean response of deposition yield is more sensitive to the changes in the voltage.

Table 4. Mean of mean response for deposition yield of chitosan/SrAg-HA on 316L SS produced at various EPD conditions, as mentioned in Table 3. 


\begin{tabular}{|l|l|l|l|l|l|}
\hline Factors & Level 1 & Level 2 & Level 3 & Level 4 & Maximum - \\
minimum
\end{tabular}

Table 5. S/N (dB) response for deposition yield of chitosan/HA coatings on 316L SS produced at various EPD conditions, as mentioned in Table 3

\begin{tabular}{|c|c|c|c|c|c|}
\hline Factors & Level 1 & Level 2 & Level 3 & Level 4 & Maximum - \\
minimum \\
\hline $\begin{array}{c}\text { Concentration } \\
\text { conc. }\end{array}$ & -26.79 & -24.10 & -17.86 & -15.7 & 11.05 \\
\hline Voltage(V) & -30.16 & -22.48 & -16.57 & -15.27 & 14.89 \\
\hline Time(min.) & -22.91 & -22.37 & -19.31 & -19.89 & 3.60 \\
\hline
\end{tabular}

For further investigation of these EPD parameters, the standard deviation effect for each control factor was observed, as shown in Figure 1. The analysis of these results elucidates that the highest deposition yield with the lowest standard deviation was obtained at A2 (3 g/L SrAg-HA), B2 (20 V), and C3 (7 min.) conditions. Moreover, the maximum-minimum S/N response suggested that the 
voltage is the most effective parameter (rank 1) with SrAg-HA concentration and deposition time (Table 7). So it is found that the voltage is most effective to the standard deviation.

Table 6 Standard deviation of mean response for deposition yield of chitosan/SrAg-HA on 316L SS produced at various EPD conditions, as mentioned in Table 3.

\begin{tabular}{|l|l|l|l|l|l|}
\hline Factors & Level 1 & Level 2 & Level 3 & Level 4 & Maximum - \\
& & & & & minimum \\
Concentration & 0.011068 & 0.009760 & 0.030807 & 0.037142 & 0.027382 \\
\hline Voltage(V) & 0.007803 & 0.018349 & 0.030635 & 0.031988 & 0.024185 \\
\hline Time(min.) & 0.024262 & 0.031506 & 0.015962 & 0.017046 & 0.015544 \\
\hline
\end{tabular}

Table 7. S/N (dB) response for standard deviation in deposition yield of chitosan/SrAg-HA coatings on 316L SS produced at various EPD conditions, as mentioned in Table 3.

\begin{tabular}{|l|l|l|l|l|l|}
\hline Factors & Level 1 & Level 2 & Level 3 & Level 4 & Maximum - \\
& & & & & minimum \\
conc. & 40.10 & 40.76 & 31.10 & 30.89 & 9.87 \\
\hline Voltage(V) & 42.74 & 36.17 & 32.92 & 31.03 & 11.71 \\
\hline Time(min.) & 35.52 & 34.38 & 36.32 & 36.64 & 2.27 \\
\hline
\end{tabular}



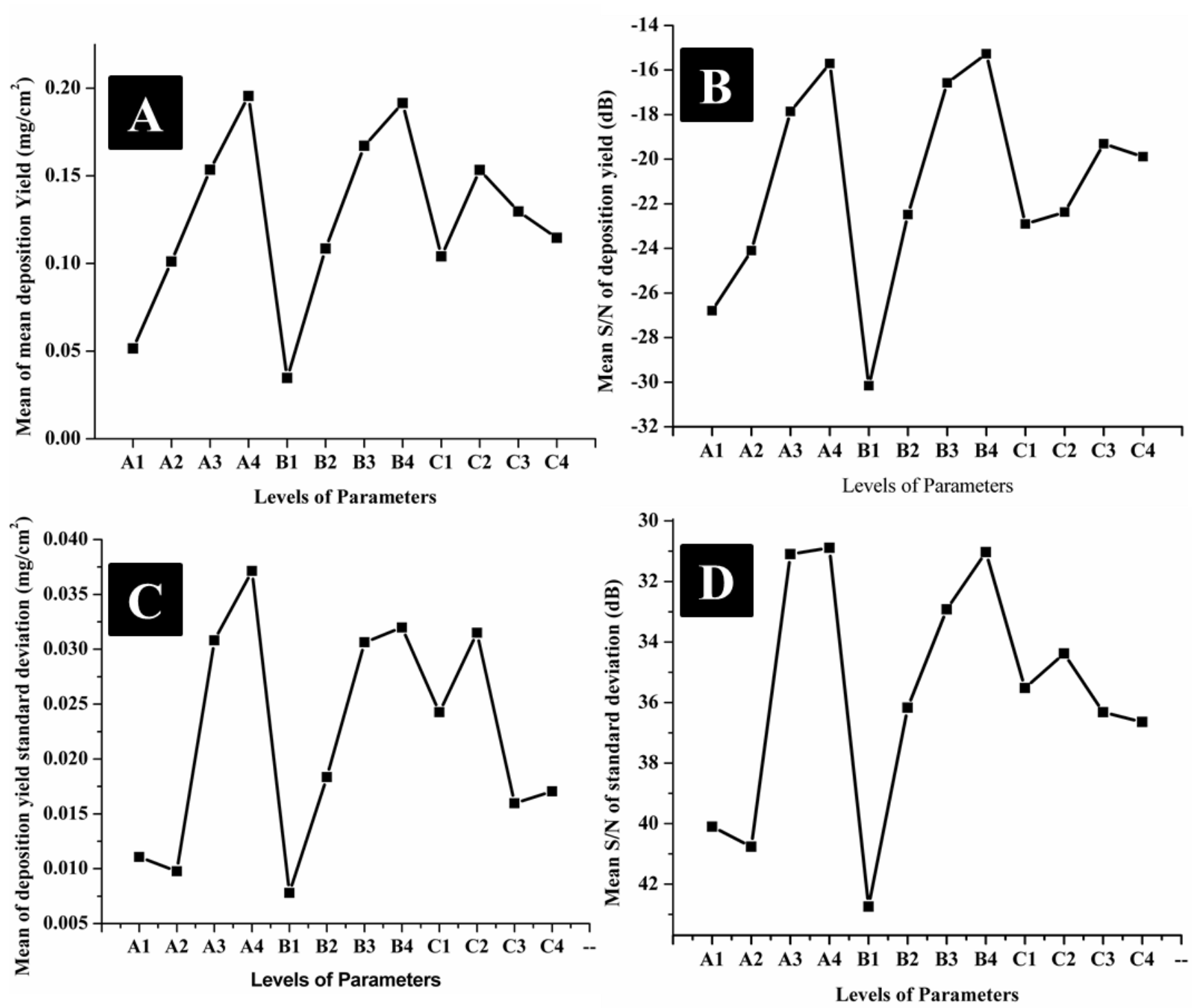

Figure 1. Effect of control factors on the deposition yield of chitosan/SrAg-HA coatings produced by EPD: (A) mean of mean deposition yield, (B) mean $\mathrm{S} / \mathrm{N}$ for deposition yield, (C) mean of standard deviation, and (D) mean $\mathrm{S} / \mathrm{N}$ for standard deviation. 


\subsection{Morphological analysis}

Although the Taguchi DoE suggests that the applied voltage of $40 \mathrm{v}$, the deposition time of $5 \mathrm{~min}$. and SrAg-HA concentration $7 \mathrm{~g} / \mathrm{L}$ are the optimum parameters to get highest deposition yield for chitosan/SrAg-HA coatings but when the standard deviation also considered it was observed that the applied voltage of $20 \mathrm{v}$, the deposition time of $7 \mathrm{~min}$. and $\mathrm{Ag} \mathrm{Sr}-\mathrm{HA}$ concentration of $5 \mathrm{~g} / \mathrm{L}$ is the best parameter for chitosan/SrAg-HA coatings. These samples were observed and compared concerning the process as well as by visual inspection. The morphology of the surface was observed by SEM, as shown in Figure 2. SEM images show that the applied voltage of 20V, the deposition time of $7 \mathrm{~min}$. and the concentration of $5 \mathrm{~g} / \mathrm{L}$ improves the distribution of $\mathrm{Ag} \mathrm{Sr}-\mathrm{HA}$ particles and the more homogenous coating was observed. So these parameters are considered as the 'best' parameters with high deposition yield and low standard deviation, and suitable surface morphology.

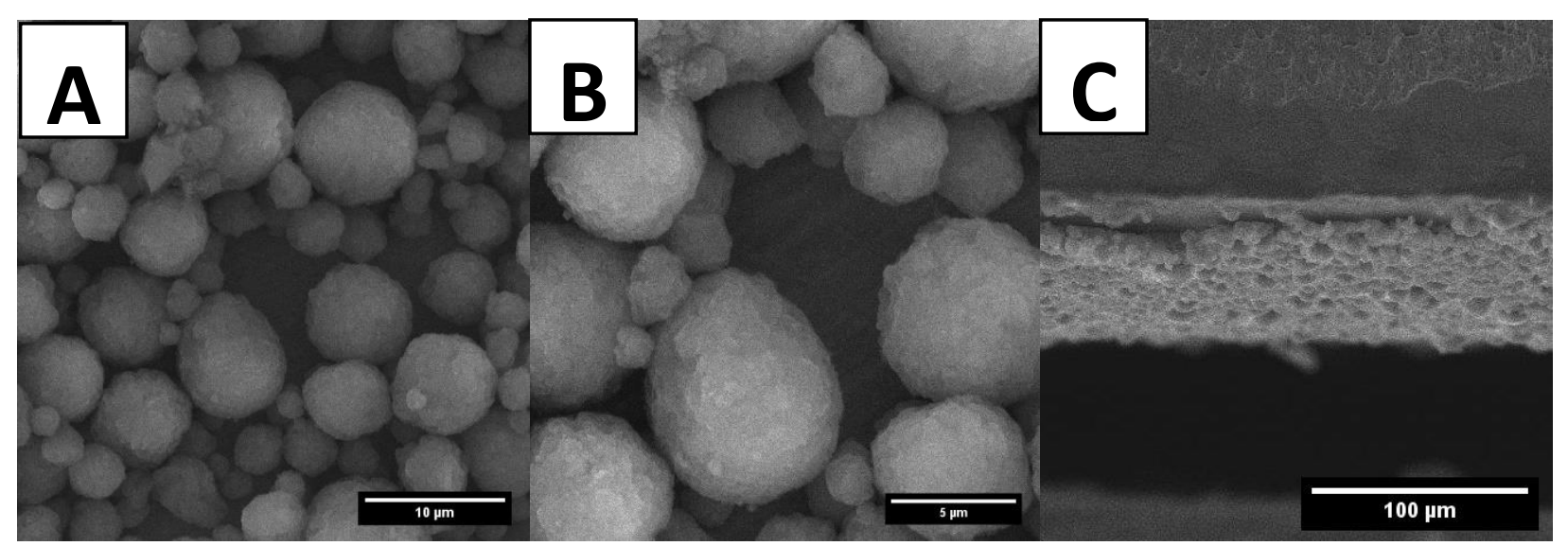

Figure 2. SEM images of chitosan/SrAg-HA coatings produced at $20 \mathrm{~V}$ of deposition voltage and 7 min. of deposition time from the suspension containing $5 \mathrm{~g} / \mathrm{L}$ of $\mathrm{Ag} \mathrm{Sr}-\mathrm{HA}$ at different magnifications; (A) image of the top surface at low magnification, (B) image of the top surface at high magnification, and (C) image at the cross-section. 
SEM analysis of optimized parameters predicted by DoE showed that the coatings are fairly homogenous (Figure 2). Figure 2A and 2C show that the $\mathrm{Sr}$ Ag-HA particles are distributed homogeneously in the Chitosan matrix. It was observed that some $\mathrm{Sr} \mathrm{Ag}-\mathrm{HA}$ particles were deposited individually while only a few $\mathrm{Sr} \mathrm{Ag}$-HA particles were agglomerated. SEM images of the cross-section showed that the chitosan/ SrAg-HA coatings developed a fairly uniform coating thickness (a film-like structure) of $\sim 5 \mu \mathrm{m}$ (Figure 2C). The similar results concerning the chitosan based composite coatings has been reported in the literature ${ }^{22-24}$.

The deposition mechanism of chitosan/HA coatings has already been explained by the Pawlick et al. ${ }^{19}$. It was suggested that the positively charged chitosan molecules encapsulate the HA particles and then HA encapsulated with HA becomes positively charged and move towards the cathode upon the application of the electric field. In the present study, chitosan/Ag Sr-HA suspension showed the zeta potential of $+30 \mathrm{mV} \pm 5 \mathrm{mV}$. The values of the zeta potential obtained in the preset study are in agreement with the literature ${ }^{1,25}$. The positive value of the zeta potential confirms the hypothesis of Pawlick et al. ${ }^{19}$. Moreover, highly uniform coatings were obtained from stable suspension of zein/Ag Sr-HA, as shown in Figure 2.

\subsection{Compositional Analysis}

Chitosan contains amino acids with high density ${ }^{1}$ and The chemical formula for HA is $\mathrm{Ca}_{5}\left(\mathrm{PO}_{4}\right)_{3}(\mathrm{OH})^{26}$. The EDX results confirm the presence of SS, HA, and chitosan (EDX was carried out at the energy of $15 \mathrm{KV}$ and working distance was $6 \mathrm{~mm}$, Figure 3). The chromium (Cr), nickel (Ni), molybdenum $(\mathrm{Mn})$ and iron $(\mathrm{Fe})$ peaks confirm the SS substrate ${ }^{14}$. The calcium and phosphorous indicate that it is HA and the presence of carbon indicates the presence of chitosan ${ }^{19}$. 


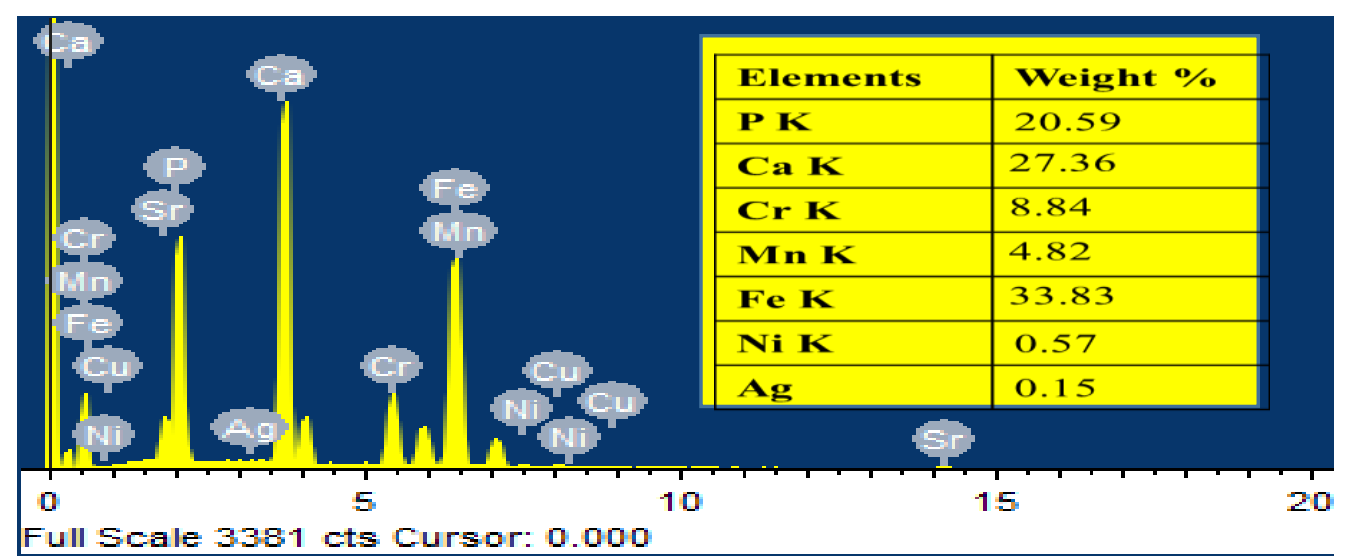

Figure 3. EDX analysis of EPD of Chitosan/AgSr-HA on 316L SS substrate by using Taguchi DoE on 316-L SS subsstrate

\subsection{Surface properties}

In order to determine the interaction of the chitosan/Ag Sr-HA coatings in the physiological environment it is important to evaluate the water contact angle. Because during the first nanoseconds water came in contact with the implant in human body. Therefore, the role of the surface wettability is important in determining the response of an implant in the human body ${ }^{27,28}$.

The contact angle measurements yielded a contact angle of $86^{\circ} \pm 2^{\circ}, 78^{\circ} \pm 3^{\circ}$, and $50^{\circ} \pm 2^{\circ}$ for the 316L SS substrate, chitosan coatings on 316L SS, and chitosan/Ag Sr-HA, respectively. The wettability results inferred that there is strong decrease in the contact angle values of chitosan/Ag $\mathrm{Sr}-\mathrm{HA}$ in comparison to the chitosan coatings. The reason for the decrease in the contact angle may be attributed to the hydrophilic nature of the HA. The similar value for the contact angle measurements were reported in literature ${ }^{1}$. Chitosan/Ag Sr-HA coatings presented the suitable wettability for the protein attachment in the physiological conditions ${ }^{25,29}$.

In order to determine the suitability of the implant for biomedical applications surface properties other than the wettability are also important for example, surface roughness and surface chemistry 23,30,31. Therefore, to gain further information concerning the suitability of the chitosan/Ag Sr-HA 
for biomedical applications, average surface roughness of the 316L SS and chitosan/Ag Sr-HA was measured. The surface roughness measurements yielded the average surface roughness of $0.5 \pm 0.1$ $\mu \mathrm{m}$ for $316 \mathrm{~L}$ SS and 1.2 $\pm 0.2 \mu \mathrm{m}$ for chitosan/Ag Sr-HA coatings. Recently, Urena et al. ${ }^{32}$ showed that the average surface roughness in the range of $1.2-1.5 \mu \mathrm{m}$ is favorable for the attachment and proliferation of bone marrow stromal (ST-2). Thus, the average surface roughness and wettability of the chitosan/Ag-sr HA coatings is expected to support the attachment of proteins and the cells for the bone regeneration applications.

\subsection{Antibacterial Studies}

The therapeutic effect associated with the release of silver ions was evaluated by tracking the antibacterial effect associated with the release of ions. Antibacterial effect of the chitosan/Ag Sr-HA coatings was studied by the agar disk diffusion test, as shown in Figure 4 . Figure 4 showed the chitosan/Ag Sr-HA coatings developed the zone of inhibition around the sample against Grampositive (S. carnosus) and Gram-negative (E. coli) bacteria. In contrast, chitosan coatings (control sample) did not develop the zone of inhibition (Figure not shown here). The antibacterial effect of chitosan/Ag Sr-HA coatings was thus attribute to the release of silver. However, in this study the release of silver ions was not evaluated quantitatively. Thus, leaving an important task for the future.

The antibacterial effect of the coatings is associated with the release of silver in an ionic form. The silver changes to ionic form upon exposure to the physiological medium. The ionic silver is highly reactive to the electron donor species. Thus, the ionic silver may rupture the walls of the bacteria and enter into the membrane hindering the DNA replication activity, which may lead to the death of the bacteria ${ }^{24,33}$. 


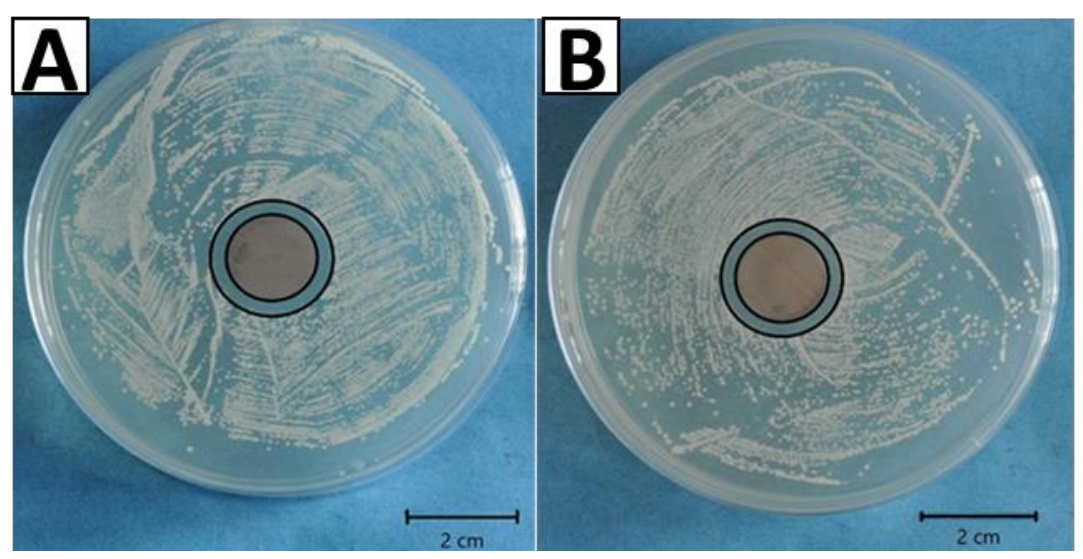

Figure 4. Inhibition halo tests for the Chitosan/Ag Sr-HA with; (A) E. coli, (B) S. carnosus.

\section{Conclusions}

1. Taguchi design of experiment approach was used to optimize chitosan/Ag Sr-HA deposited on 316L SS via EPD. The suspension composition (concentration of Ag Sr-HA in the chitosan solution) and EPD parameters were optimized in terms of highest deposition yield with lowest standard deviation.

2. Chitosan/Ag Sr-HA composite coatings obtained from the optimum parameter showed the uniform distribution Ag Sr-HA particles in the chitosan matrix. SEM image at the crosssection showed that the coating thickness is $\sim 5 \mu \mathrm{m}$.

3. EDX analysis confirmed the presence of Ag Sr-HA and chitosan in the coatings.

4. Wettability and surface roughness studies confirmed the suitability of chitosan/Ag Sr-HA coatings for the biomedical applications.]

5. The effect for the release of silver ions was traced by the antibacterial studies. Chitosan/Ag Sr-HA showed the potent antibacterial effect against E. coli and S. carnosus. 
In the future it will be interesting to investigate the effect for the release of silver ions on the biocompatibility of the coatings.

\section{Acknowledgments}

MAUR is thankful to the HEC for the award of SRGP \#2703.

\section{References}

(1) Avcu, E.; Baştan, F. E.; Abdullah, H. Z.; Ur Rehman, M. A.; Yıldıran Avcu, Y.; Boccaccini, A. R.; Ba, F. E.; Abdullah, H. Z. Electrophoretic Deposition of Chitosan-Based Composite Coatings for Biomedical Applications: A Review. Prog. Mater. Sci. 2019, 103 (January), 69-108. https://doi.org/10.1016/j.pmatsci.2019.01.001.

(2) Atiq, M.; Rehman, U.; Azeem, M.; Schubert, D. W.; Boccaccini, A. R.; Rehman, M. A. U.; Munawar, M. A.; Schubert, D. W.; Boccaccini, A. R. Electrophoretic Deposition of Chitosan/Gelatin/Bioactive Glass Composite Coatings on 316L Stainless Steel: A Design of Experiment Study. Surf. Coatings Technol. 2019, 358 (November 2018), 976-986. https://doi.org/10.1016/j.surfcoat.2018.12.013.

(3) Ramakrishna, S.; Mayer, J.; Wintermantel, E.; Leong, K. W. Biomedical Applications of Polymer-Composite Materials: A Review. Compos. Sci. Technol. 2001, 61 (9), 1189-1224. https://doi.org/10.1016/S0266-3538(00)00241-4.

(4) Moskalewicz, T.; Zych, A.; Kruk, A.; Kopia, A.; Zimowski, S.; Sitarz, M.; Cieniek, Ł. Electrophoretic Deposition and Microstructure Development of Si3N4/Polyetheretherketone Coatings on Titanium Alloy. Surf. Coatings Technol. 2018, 350 (July), 633-647. https://doi.org/10.1016/j.surfcoat.2018.07.059. 
(5) Sak, A.; Moskalewicz, T.; Zimowski, S.; Cieniek, Ł.; Dubiel, B.; Radziszewska, A.; Kot, M.; Łukaszczyk, A. Influence of Polyetheretherketone Coatings on the Ti-13Nb-13Zr Titanium Alloy's Bio-Tribological Properties and Corrosion Resistance. Mater. Sci. Eng. C 2016, 63, 52-61. https://doi.org/10.1016/j.msec.2016.02.043.

(6) Fedrizzi, L.; Crousier, J.; Bonora, P. ???L; Crousier, J. ???P. Corrosion Mechanisms of an AISI Type 316L Sintered Stainless Steel in Sodium Chloride Solution. Mater. Corros. 1991, 42 (8), 403-409. https://doi.org/10.1002/maco.19910420804.

(7) Atiq Ur Rehman, M.; Bastan, F. E.; Haider, B.; Boccaccini, A. R.; Rehman, M. A. U.; Bastan, F. E.; Haider, B.; Boccaccini, A. R. Electrophoretic Deposition of PEEK/Bioactive Glass Composite Coatings for Orthopedic Implants: A Design of Experiments (DoE) Study. Mater. Des. 2017, 130 (March), 223-230. https://doi.org/10.1016/j.matdes.2017.05.045.

(8) Anthony, P. P.; Gie, G. A.; Howie, C. R.; Ling, R. S. Localised Endosteal Bone Lysis in Relation to the Femoral Components of Cemented Total Hip Arthroplasties. J. Bone Joint Surg. Br. 1990, 72 (6), 971-979.

(9) Kim, S. Changes in Surgical Loads and Economic Burden of Hip and Knee Replacements in the US: 1997-2004. Arthritis Care Res. 2008, 59 (4), 481-488. https://doi.org/10.1002/art.23525.

(10) M Navarro, A Michiardi, O Castaño, J. . P.; M. Navarro, A. Michiardi, O. C.; Biomaterials, o and J. A. Planell; M Navarro, A Michiardi, O Castaño, J. . P.; M. Navarro, A. Michiardi, O. C.; Biomaterials, ̃o and J. A. Planell; M Navarro, A Michiardi, O Castaño, J. . P. Biomaterials in Orthopaedics. J. R. Soc. Interface 2008, 5 (July), 1137-1158. https://doi.org/10.1007/978-3-319-14845-8_7. 
(11) Raddaha, N. S.; Cordero-Arias, L.; Cabanas-Polo, S.; Virtanen, S.; Roether, J. A.;

Boccaccini, A. R. Electrophoretic Deposition of Chitosan/h-BN and Chitosan/h-BN/TiO2 Composite Coatings on Stainless Steel (316L) Substrates. Materials (Basel). 2014, 7 (3), 1814-1829. https://doi.org/10.3390/ma7031814.

(12) Virk, R. S.; Atiq, M.; Rehman, U.; Munawar, M. A.; Schubert, D. W.; Goldmann, W. H.; Dusza, J.; Boccaccini, A. R. Curcumin-Containing Orthopedic Implant Coatings Deposited on Poly-Ether-Ether-Ketone/Bioactive Glass/Hexagonal Boron Nitride Layers by Electrophoretic Deposition. Coatings 2019, 9 (572).

(13) Pishbin, F.; Simchi, A.; Ryan, M. P.; Boccaccini, A. R. Electrophoretic Deposition of Chitosan/45S5 Bioglass Composite Coatings for Orthopaedic Applications. Surf. Coatings Technol. 2011, 205 (23-24), 5260-5268. https://doi.org/10.1016/j.surfcoat.2011.05.026.

(14) Baştan, F. E. F. E. F. E.; Atiq Ur Rehman, M.; Avcu, Y. Y. Y. Y.; Avcu, E.; Üstel, F.; Boccaccini, A. R. A. R.; Rehman, M. A. U.; Avcu, Y. Y. Y. Y.; Avcu, E.; Üstel, F.; Boccaccini, A. R. A. R. Electrophoretic Co-Deposition of PEEK-Hydroxyapatite Composite Coatings for Biomedical Applications. Colloids Surfaces B Biointerfaces 2018, 169, 176182. https://doi.org/10.1016/j.colsurfb.2018.05.005.

(15) Lee, J. H.; Jang, H. L.; Lee, K. M.; Baek, H.-R.; Jin, K.; Hong, K. S.; Noh, J. H.; Lee, H.-K. In Vitro and in Vivo Evaluation of the Bioactivity of Hydroxyapatite-Coated Polyetheretherketone Biocomposites Created by Cold Spray Technology. Acta Biomater. 2013, 9 (4), 6177-6187. https://doi.org/10.1016/j.actbio.2012.11.030.

(16) Farrokhi-Rad, M.; Shahrabi, T.; Mahmoodi, S.; Khanmohammadi, S. Electrophoretic Deposition of Hydroxyapatite-Chitosan-CNTs Nanocomposite Coatings. Ceram. Int. 2017, 
43 (5), 4663-4669. https://doi.org/10.1016/j.ceramint.2016.12.139.

(17) Besra, L.; Liu, M. A Review on Fundamentals and Applications of Electrophoretic Deposition (EPD). Prog. Mater. Sci. 2007, 52 (1), 1-61. https://doi.org/10.1016/j.pmatsci.2006.07.001.

(18) Boccaccini, A. R.; Keim, S.; Ma, R.; Li, Y.; Zhitomirsky, I.; R.Boccaccini, A.; Keim, S.; Ma, R.; Li, Y.; Zhitomirsky, I.; Boccaccini, A. R.; Keim, S.; Ma, R.; Li, Y.; Zhitomirsky, I. Electrophoretic Deposition of Biomaterials. J. R. Soc. Interface 2010, 7 Suppl 5 (May), S581-S613. https://doi.org/10.1098/rsif.2010.0156.focus.

(19) Pawlik, A.; Atiq, M.; Rehman, U.; Nawaz, Q.; Bastan, F. E.; Sulka, D.; Boccaccini, A. R. Fabrication and Characterization of Electrophoretically Deposited Chitosan-Hydroxyapatite Composite Coatings on Anodic Titanium Dioxide Layers. Electrochim. Acta 2019, 307, 465-473. https://doi.org/10.1016/j.electacta.2019.03.195.

(20) Bastan, F. E.; Erdogan, G.; Moskalewicz, T.; Ustel, F. Spray Drying of Hydroxyapatite Powders: The Effect of Spray Drying Parameters and Heat Treatment on the Particle Size and Morphology. J. Alloys Compd. 2017, 724, 586-596. https://doi.org/10.1016/j.jallcom.2017.07.116.

(21) Ur Rehman, M. A.; Ferraris, S.; Goldmann, W. H.; Perero, S.; Bastan, F. E.; Nawaz, Q.; Confiengo, G. G. Di; Ferraris, M.; Boccaccini, A. R. Antibacterial and Bioactive Coatings Based on Radio Frequency Co-Sputtering of Silver Nanocluster-Silica Coatings on PEEK/Bioactive Glass Layers Obtained by Electrophoretic Deposition. ACS Appl. Mater. Interfaces 2017, 9 (38), 32489-32497. https://doi.org/10.1021/acsami.7b08646.

(22) Atiq, M.; Rehman, U.; Bastan, F. E.; Nawaz, Q.; Goldmann, W. H.; Maqbool, M.; Virtanen, 
S.; Boccaccini, A. R. Electrophoretic Deposition of Lawsone Loaded Bioactive Glass ( BG )/ Chitosan Composite on Polyetheretherketone ( PEEK )/ BG Layers as Antibacterial and Bioactive Coating. J. Biomed. Mater. Res. Part A 2018, 1-12. https://doi.org/10.1002/jbm.a.36506.

(23) Pishbin, F.; Mouriño, V.; Flor, S.; Kreppel, S.; Salih, V.; Ryan, M. P.; Boccaccini, A. R.; Mourino, V.; Flor, S.; Kreppel, S.; Salih, V.; Ryan, M. P.; Boccaccini, A. R.; Mouriño, V.; Flor, S.; Kreppel, S.; Salih, V.; Ryan, M. P.; Boccaccini, A. R. Electrophoretic Deposition of Gentamicin-Loaded Bioactive Glass/Chitosan Composite Coatings for Orthopaedic Implants. ACS Appl. Mater. Interfaces 2014, 6 (11), 8796-8806. https://doi.org/10.1021/am5014166.

(24) Pishbin, F.; Mouriño, V.; Gilchrist, J. B.; McComb, D. W.; Kreppel, S.; Salih, V.; Ryan, M. P.; Boccaccini, A. R. Single-Step Electrochemical Deposition of Antimicrobial Orthopaedic Coatings Based on a Bioactive Glass/Chitosan/Nano-Silver Composite System. Acta Biomater. 2013, 9 (7), 7469-7479. https://doi.org/10.1016/j.actbio.2013.03.006.

(25) Avcu, E.; Yıldıran Avcu, Y.; Baştan, F. E.; Rehman, M. A. U.; Üstel, F.; Boccaccini, A. R.; Yasemin, Y.; Erdem, F.; Atiq, M.; Rehman, U.; Üstel, F.; Boccaccini, A. R. Tailoring the Surface Characteristics of Electrophoretically Deposited Chitosan-Based Bioactive Glass Composite Coatings on Titanium Implants via Grit Blasting. Prog. Org. Coatings 2018, 123 (May), 362-373. https://doi.org/10.1016/j.porgcoat.2018.07.021.

(26) Baştan, F. E.; Özbek, Y. Y. Producing Antibacterial Silver-Doped Hydroxyapatite Powders with Chemical Precipitation and Reshaping in a Spray Dryer. Mater. Tehnol. 2013, 47 (4), $431-434$. 
(27) Bumgardner, J. D.; Wiser, R.; Elder, S. H.; Jouett, R.; Yang, Y.; Ong, J. L. Contact Angle, Protein Adsorption and Osteoblast Precursor Cell Attachment to Chitosan Coatings Bonded to Titanium. J. Biomater. Sci. Polym. Ed. 2003, 14 (12), 1401-1409. https://doi.org/10.1163/156856203322599734.

(28) Menzies, K. L.; Jones, L. The Impact of Contact Angle on the Biocompatibility of Biomaterials. Optom. Vis. Sci. 2010, 87 (6), 387-399. https://doi.org/10.1097/OPX.0b013e3181da863e.

(29) Heise, S.; Wirth, T.; Höhlinger, M.; Hernández, Y. T.; Ortiz, J. A. R.; Wagener, V.; Virtanen, S.; Boccaccini, A. R. Electrophoretic Deposition of Chitosan/Bioactive Glass/Silica Coatings on Stainless Steel and WE43 Mg Alloy Substrates. Surf. Coatings Technol. 2018, 344, 553-563. https://doi.org/10.1016/j.surfcoat.2018.03.050.

(30) Chen, Z.; Boström, T. Electrophoretically Deposited Carbon Nanotube Spectrally Selective Solar Absorbers. Sol. Energy Mater. Sol. Cells 2016, 144, 678-683. https://doi.org/10.1016/j.solmat.2015.10.016.

(31) Singh, R.; Atiq, M.; Rehman, U.; Boccaccini, A. R. PEEK Based Biocompatible Coatings Incorporating $\mathrm{H}-\mathrm{BN}$ and Bioactive Glass by Electrophoretic Deposition Institute of Biomaterials, Department of Materials Science and Engineering, * Corresponding Author : Aldo.Boccaccini@ww.Uni-Erlangen.de Composite Coat. 2018, 82 (1), 89-95.

(32) Ureña, J.; Tsipas, S.; Jiménez-Morales, A.; Gordo, E.; Detsch, R.; Boccaccini, A. R. Cellular Behaviour of Bone Marrow Stromal Cells on Modified Ti-Nb Surfaces. Mater. Des. 2018, 140, 452-459. https://doi.org/10.1016/j.matdes.2017.12.006.

(33) Simchi, A.; Tamjid, E.; Pishbin, F.; Boccaccini, A. R. Recent Progress in Inorganic and 
Composite Coatings with Bactericidal Capability for Orthopaedic Applications.

Nanomedicine Nanotechnology, Biol. Med. 2011, 7 (1), 22-39.

https://doi.org/10.1016/j.nano.2010.10.005. 